\title{
NORMATIWITEIT VERSUS NEUTRALITEIT IN DIE KOMMUNIKASIEWETENSKAPPE
}

Die tema waaroor ek vandag met $\mathrm{u}$ moet spreek, is in die ware wese van die kommunikasiewetenskappe baie moeilik en wel omdat die twee begrippe, normatiwiteit en neutraliteit, in die eerste plaas bitter moeilik omskryfbaar is en in die tweede plaas in kommunikatiewe verband met mekaar vervleg is. In die opset van die kommunikasiewetenskap word daardie normatiwiteit wat ek met die oog op hierdie referaat moet beklemtoon, naamlik tot groot hoogte bepaal deur die mate waarin die kommunikator „neutraal” kan wees.

1. Ek neem aan dat die normatiwiteit wat die organiseerders van hierdie byeenkoms op die oog het, geestelike normatiwiteit is, meer bepaald religieuse normatiwiteit, finaliter Christelike normatiwiteit. Daar is naamlik in die kommunikasiewetenskappe ook 'n reeks ander norme wat in die praktyk gewigtig is, om die minste daarvan te sê. Onder hierdie norme sou ek wil tel: ekonomiese norme (sonder baie groot ekonomiese hulpmiddele is die massakommunikasiewese immers onbestaanbaar); juridiese norme wat op gevaar af van 'n konfrontasie met die howe en die owerheid in elk geval nagekom moet word; taalnorme omdat die kommunikasie wat hier ter sprake is, nooit anders as deur taal kan geskied nie. Dit kom my daarom voor dat die normatiwiteit wat hier ter sake is, die norme van die etiese en die religieuse is.

Bespreek ons neutraliteit binne hierdie raamwerk, kom ons eweneens by die kernwaarheid uit dat alle ernstige kommunikasie religieus bepaald is. In hierdie verband wil ek my graag aansluit by die uitspraak van Jon Kennedy, Kanadese teoloog wat aan die Universiteit van Kalifornië ook 'n meestersgraad in die joernalistiek behaal het met 'n verhandeling wat uiteindelik gepubliseer is onder die titel The Reformation of Journalism. Kennedy verklaar (p 34) „It is not hard to show... that all journalists act on religious motives". Ek meen dat dit waar is van alle kommunikasie op hoë vlak.

Hiermee wil ek allermins te kenne gee dat die joernaliste 'n groep voorbeeldige Christenmense is. Kennedy stip dit dan ook aan deur 'n aantal voorbeelde te noem wat eintlik areligieus is. Die joernalistiek sê hy, kan religieus gemotiveer 
word om 'n kapitalistiese saak te dien, soos in die geval van die Wall Street Journal. Die motief kan ook ,empire building for its own sake" wees, soos geopenbaar deur daardie koerantkettings wat op redaksionele neutraliteit aanspraak maak, sodat elk van die koerante teen sy eie snelheid kan ontwikkel. Voorbeelde in ons tyd is die internasionale Thompson-groep met belange dwarsdeur die Engelstalige wêreld (daar is sowat 180 koerante en tydskrifte sowel as beeldradiodienste wat aan die groep behoort) en die nasionale Springer-groep in Duitsland. Die motief kan ook wees minagting van die bestaande orde, soos geopenbaar deur die sogenaamde ondergrondse pers in baie lande. Politieke ambisie het William Randolph Hearst, wat die Amerikaanse geelpers tot die spits gedryf en die Spaans-Amerikaanse oorlog veroorsaak het, aangedryf, terwyl die stryd om "sexual liberation" die homoseksuele tweeweeklikse The Advocate van Los Angeles motiveer. Meer newelagtige opvattinge soos „openbare diens”, „bevordering van die Amerikaanse lewenswyse" ens motiveer volgens Kennedy waarskynlik die meeste Amerikaanse joernaliste. Maar al hierdie motiewe en opvattinge moet tot die lewens- en wêreldbeskoulike herlei word, wat uiteindelik religieus gewortel is, sy dit dan pro-Christelik, a-Christelik of anti-Christelik.

Hoe positief 'n suiwer Christelike oortuiging in die joernalistiek kan deurwerk, skets Gay Talese in sy werk The New York Times, the Kingdom and the Power, aan die hand van die voorbeeld van James Reston, van wie hy skryf: „There was finally in Reston's style an element far more significant than his writing skill or wit, and this was his persuasive tone of moralism and idealism that brought to his readers the inner elevation of a good Sunday sermon - James Reston was something of a preacher. His strict Scotch Presbyterian mother had wanted him to become a preacher, and as a Timesman he had become one, his column being the podium from which he could spread his Calvinistic view of life throughout the land, thrilling thousands with his sound logic and clarity, influencing students, educators, and politicians, sometimes infuriating such presidents as Eisenhower, who once asked, „who the hell does Reston think he is, telling me how to run the country?" Reston expected great things from the mighty, not muscle and heart, but also some piety and nobility 
of spirit; and yet, when they failed him, as they most often did, he did not damn them, but rather foresaw signs of redemption and hope. This was Reston's special appeal. He commuted hope... his America was a positive place of rightthinking people, and God was on our side - it was as it had been during World War II".

Sedert die ontstaan van die koerant in die ná-Renaissancetydperk was neutraliteit nog nooit en nog nêrens normatiewe werklikheid nie, in weerwil van alle aansprake deur joernaliste op sogenaamde onsydigheid, onpartydigheid, redelikheid en billikheid. In die verlede was dit miskien meer opvallend as deesdae - die kommunikasiewese het meer subtiel geword maar kantkiesery was nog altyd deel van die kommunikasiemedia. 'n Steekproefie deur die geskiedenis van byna vier eeue van gedrukte nuusmededelinge heen lewer daarvan oorvloedige bewys. Een van die uitvoerigste van hierdie ou-ou nuusblaaie wat gedruk is sowat dertig jaar voordat die koerant eintlik sy beslag gekry het - 'n vaste naam, gereelde verskyningsdag en volgnommers - bevat onder meer die volgende „nieumaren": Uit Londen: „Hier wordt oock sterck gheseyt van de doot van den Coninck van Spaengen: God gheve dat het eens mach waarachtig bevonden worden".

Hierdie „koerant”, agt velle van kwarto-formaat, waarvan ses bedruk was, het in 1590 te Haarlem verskyn en die slotparagraaf laat geen twyfel oor die gesindheid van die uitgewers nie. Dit lui naamlik: „Dit is al't ghene dat wy voor desen tijdt voor nieunaren hebben. De Heere wil ons verleenen dat ons salich is. Amen".

In Suid-Afrika was dit met neutraliteit nooit anders gesteld nie. Die land se eerste werklik partikuliere koerant, die South African Advertiser van George Greig. Thomas Pringle en John Fairbairn, was sommer van die tweede en derde uitgawe af met die Goewerneur, lord Charles Somerset, in die weer oor spraak- en persvryheid. Aan Afrikaanse kant het die eintlike koerantgeskiedenis by $\mathrm{De}$ Zuid-Afrikaan begin, wat reeds in sy eerste hoofartikel sterk standpunt in belang van die Kaapse Nederlanders ingeneem het. Dit het metterjare vaste gebruik geword dat die Christelik-Nasionale vlag aan die mas van nuwe Afrikaanse koerante gespyker word. Dit het $\mathrm{dr}$ Malan in die eerste uitgawe van Die Burger gedoen en dr Verwoerd in die eerste hoofartikel van Die Transvaler. 
Op dieselfde wyse kan elke koerant en uok die SAUK in Suid-Afrika getipeer word. Die Rand Daily Mail is oorwegend Progressief-Liberaal, die Star Verenigde Party-ProgressiefLiberaal, die Sunday Times Schwartz-Progressief-Liberaal ens ens. Ook ten opsigte van die godsdiens is daar in Suid-Afrika geen werklik neutrale koerant nie: die Engelstalige koerante steun in hoofsaak die kerkgroep wat in die SA Raad van Kerke saamgetrek is, met die Church of the Province aan die spits, en die Afrikaanse koerante sonder uitsondering die drie Afrikaanse kerke, met die klem in die besonder op die standpunte van die Ned Geref Kerk. Die SAUK weer op sy beurt soveel as moontlik uit sy programme in al die tale wat hy benut, alles wat vir alle gevestigde kerke aanstootlik kan wees. Ons kan hierby volstaan: in Suid-Afrika is ál die media by een of ander politieke, kerklike of maatskaplike rigting betrokke. Daar is geen neutraliteit nie.

\section{Normatiwiteit}

Al sou ons normatiwiteit en neutraliteit dan nie in slagorde teen mekaar kan opstel nie, beteken dit allermins dat ons die normatiwiteit van die Suid-Afrikaanse media nie nader kan bespreek nie. Besinning oor hierdie aangeleentheid moes trouens lankal plaasgevind het. Hierby word bedoel ingeligte besinning, nie die los snedige opmerkinge en aanmerkinge wat so dikwels oor "die pers" uitgespreek word nie. Daar is baie mense in Suid-Afrika wat die pers graag met 'n banvloek sou wil tref, soms geregverdig, meer dikwels nie.

Voordat in die besonder tot 'n gevolgtrekking gekom kan word oor die vraag of iets, en dan wat, met die Suid-Afrikaanse media skort, is 'n kort opsomming van die regmatige funksies van die media noodsaaklik, anders redeneer ons in die wind en by mekaar verby.

Feitlik alle skrywers oor die kommunikasiemedia en -wetenskap is dit eens dat die media vyf regverdigbare funksies het:

2.1. Die heel eerste is dié van feitemededeling, die verstrekking van nuwe kontingente kennis. Die koerante, die radiowese en die beeldradio probeer wêreldwyd universeel betekenisvolle nuwe kennis wêreldkundig maak, in teenstelling met die tydskrifwese wat meesal in baie hoër mate as die 
koerantwese tot bepaalde leserskringe gerig word. Die mediese tydskrifte is bv vir die leek onbegryplik en daarom bykans ontoeganklik.

2.2. Die tweede algemeen erkende funksie is dié van kommentaar en kritiek. Normatief word hierdie funksie op twee maniere volbring: In die eerste plaas word die agtergrond van feitelike gebeure nader toegelig, onder meer deur historiese of verwante agtergrondmateriaal, maar in die tweede plaas deur die uitspreek van oordele en kritiek oor die doen en late van owerheidspersone, -liggame, politieke partye, selfs kerklike en maatskaplike samelewingsgroepe en -bindinge. Dit is heeltemal geregverdig. Baie mense wil juis 'n koerant of nuustydskrif koop om 'n tweede, dalk meer gesaghebbende mening oor 'n gebeurtenis, tendens of verskynsel te kry.

2.3. Die derde erkende funksie van die media, sy dit dan die radio, koerant, beeldradio of tydskrif, is die verskaffing van vermaak, afleiding en ontspanning. Dit is ' $n$ volkome geregverdigde funksie: sonder sy ligter oomblikke sou die menslike bestaan bra swaarmoedig en swaarwigtig gewees het.

2.4. Die vierde funksie is 'n ekonomiese, wat ook tweërlei van aard is. Deur betaalde reklame en ekonomiese beriggewing en kommentaar speel die kommunikasiemedia 'n heel belangrike rol in die lands- en wêreldekonomie.

2.5. Die vyfde erkende funksie van die media is die lewering van allerlei openbare diensies. Dit kan strek van die bekendmaking dat 'n kinderkonsert plaasvind, die aankondiging van 'n Sondag se kerkdienste, tot die aankondiging van groot komende gebeurtenisse. Meesal het 'n aankondiging soos 'n noodberig oor die radio weinig algemene nuuswaarde, behalwe vir ' $n$ heel klein kring, maar die meeste media doen tog hieraan mee as blyk van welwillendheid teenoor lesers of hoorders. Tot sulke dienslewering leen die beeldradio hom nie. Sy tyd is eenvoudig daarvoor te duur.

2.6. Daar is ook 'n groep joernaliste wat aan die nuusmedia ' $n$ sesde funksie, en daarby ' $n$ heel belangrike, wil toeken. Dit is naamlik dat die pers, en dan in die besonder die koerante en nuustydskrifte, die radio en die beeldradio, die 
rol van die "vierde stand" in die samelewing moet beklee. Dit kom daarop neer dat hierdie vierde stand as 't ware 'n regeerfunksie moet hê, met die klem in die besonder op die openbaarmaking van skandale in hoë kringe.

Regmatig kan hierdie aanspraak nooit wees nie, al word dit in die jongste jare ook in Afrikaanse perskringe gehoor. Die media, behalwe die radio en beeldradio, in daardie lande wat nog demokraties is, is steeds in private besit, wat beteken dat die publiek, anders as deur weiering om dié blaaie te lees en uitsendings aan te hoor, geen regstreekse seggenskap in die beheer en bestuur van sodanige media het nie. Oor hul kom en gaan word geen demokratiese stemminge gehou nie, soos ten opsigte van parlemente geskied, en van wat binne so ' $n$ instelling gebak en gebrou word, weet niemand ooit iets met sekerheid nie. Die nuusmedia kan ewe min die vierde stand wees as 'n geheime organisasie of ekonomiese monopolisties georganiseerde maatskappye. Baie koerante in SuidAfrika smaal bv oor selfaangestelde sedebewakers, maar wil self morele en politieke beleidmakers wees, die sg "King Makers".

Dit is terloops opvallend dat die media oor hul eie aangeleenthede presies so swygsaam as die manne om pres Nixon ná die Watergate inbraak was en is.

Ek wil die vierde stand- of waghond-oor-die-vryheid-aanspraak van die pers, radio en beeldradio as onbestaanbaar met die volksvryheid afwys, behalwe vir sover die waghondfunksie binne die eerste twee funksies van die media tot sy reg kan kom.

\section{Kritiese ontleding}

3.1. Wanneer gesê word dat dit die taak van die kommunikasiemedia is om as primêre bron van kontingente inligting te dien, word meer as 'n mondvol gesê. Daar word trouens 'n eis gestel wat wesenlik onuitvoerbaar is, en wel om die volgende redes:

(a) Dit is vir koerante, radiodienste en die beeldradio onmoontlik om alle ter sake nuwe inligting wat op ' $n$ bepaalde dag beskikbaar is, te publiseer: Van sekere dinge weet die betrokke redaksie nie - dit het nie onder die aandag gekom nie; die verslaggewers is op die verkeerde voet betrap; bepaal- 
de nuus is opsetlik aan 'n medium weerhou. 'n Goeie voorbeeld van laasgenoemde in Suid-Afrika is die onlangse geboorte van die Rosenkowitz-sesling in Kaapstad. Republikeinse Pers van Natal het die wêreldregte op die beeltenis van die babas gekoop. Rapport was haastig by om 'n aandeel in die monopolie te verkry, met die gevolg dat die Sondag ná die geboorte in die koerantwêreld bekend sal staan as een van die rampspoedigste in die geskiedenis van die Sunday Times. Terwyl Rapport se voorblad redelik goeie foto's (vir die omstandighede) van vader, moeder en al ses babas gedra het, moes die Sunday Times met vae pentekeninge tevrede wees. Vir my as oudjoernalis was dit moontlik om die kragtaal van die Sunday Times-manne op die bewuste oggend hier in Potchefstroom te hoor! In Londen se Fleet Street was dit enkele maande gelede dié skindernuus dat twee van Londen se beste nuusredakteurs summier ontslaan is omdat hulle toegelaat het dat hulle met foto's oor die kamertonele van die deurlugtige lords Lambton en Jellicoe gescoop word.

(b) As dit norm is dat 'n koerant al die nuus wat die moeite werd is, moet plaas, is die tweede rede waarom deel van die nuus nie die paal haal nie, nie die gevolg van nalatigheid of slegtigheid nie, maar gebrek aan ruimte. Die totale daaglikse toevloei van nuus en nuuskommentaar uit alle bronne (die nasionale en internasionale nuusdienste, eie redaksielede en korrespondente, en ander nuusbronne wat daagliks op die groot Suid-Afrikaanse dagblaaie toesak), beloop enigiets van 150000 tot 250000 woorde. Selfs met die fynste keuring en redigering kan gewoonlik nie met meer as 'n kwart tot 'n derde van hierdie nuustoestroming klaargespeel word nie. By die radio en beeldradio gaan dit nog veel erger toe: 'n gewone nuusbulletin van tien minute oor die radio bevat gewoonlik nie meer as in die omgewing van 1200 woorde nie, terwyl beeldradio die soeklig op 'n nog kleiner segment van die nuuswerklikheid moet laat val.

Kortom: Aan die norm dat die nuus sowel universeel as volledig behoort te wees, kan geen van die media na behore voldoen nie, selfs al was hulle nie nalatig of sorgeloos in die nuusversameling nie.

3.2. En hieruit spruit dadelik ' $n$ tweede afwyking van die norm van volledigheid, billikheid e $\mathrm{d} \mathrm{m}$ in die beriggewing 
voort. In die proses van nuuskeuring (wat ook weglating impliseer) is dit die voorkeure en vooroordele van slegs enkele mense wat deurslag gee by die finale beslissing oor wat geplaas of uitgesaai word en wat nie. En daardie keuring is bloot subjektief: daar bestaan immers geen objektiewe maatstaf by nuuskeuring nie. Deurslaggewend is dit wat vir 'n enkeling of 'n klein groepie "nuuswaardig" is of die ,nuuswaardigste" lyk. Daar is nie so iets soos 'n Portugese punteskaal wat in atletiek die waarde van prestasies meet nie. Dit gaan louter om eie aanvoeling. En hier is die norm rekbaar, inderdaad baie rekbaar.

\section{Kommentaar}

As dit by die blote keuring van die nuus reeds normatief "onvoorspelbaar" toegaan, dan is dit by die lewering van kommentaar 'n nog veel meer onbevredigende toestand. Kommentaar, of dit nou om 'n politieke gebeurtenis, 'n sosiale tendens, 'n aanvegbare boek of wat ook al gaan, kan nooit anders as prinsipieel gefundeerd wees nie. As daar één plek in die kommunikasiemedia is waar neutraliteit nie kan bestaan nie, is dit by die beoordeling van gebeure, toestande en verskynsels.

Die vraag wat hom onvermydelik op die voorgrond druk, is saaklik die volgende: Volgens watter beginselstandpunt lewer die kommentator sy oordeel?

En dit is 'n vraag waarop antwoorde in die Suid-Afrikaanse kommunikasiemedia bitter moeilik gevind kan word. Daar is in ons land in sy kommunikasiewese naamlik nog meer uitgangspunte as volks- en etniese groepe, elk waarvan binne ons demokratiese bestel in elk geval teoreties bestaansreg het.

Binne die raamwerk van hierdie oorweging is dit gans en al onmoontlik om die verskillende denkbare uitgangspunte wat tot lewens- en wêreldbeskoulike standpuntnames lei, te probeer ontleed. Daar is eenvoudig te veel. Ons kan slegs op enkele wys:

In sy grondwet het die Parlement van die Republiek hom aan 'n besondere belydenis verbind, maar ook slegs in breë terme. Wet 32 van 1961 erken in sy aanhef (wat as 'n geloofsbelydenis kan deurgaan) naamlik die Drie-enige God van die Christelike kerke as die opperste bron van gesag, en verbind 
hom dan meer spesifiek „om die wet en orde daarin (die land) te handhaaf; om die geluk en geestelike en stoflike welvaart van almal te bevorder ..." en dan wel binne 'n grondwet wat die beste sal aanpas by die tradisies en geskiedenis van ons vaderland.

Sonder om begrippe onnodig te rek, sou 'n mens kan sê dat die Christelike beginsel in die Grondwet as norm, ook vir die kommunikasiemedia, vasgelê is, maar dan kom daar nog geen antwoord nie op die vraag: die Christelike beginsels soos deur wie vertolk? Die Afrikaanse kerke? Die Rooms-Katolieke of die Anglikaanse of die Lutherse Kerk? Of die Christelike Instituut? Of die Ekumeniese Sinodes binne en buite SuidAfrika?

Die werklikhede van die land maak dit eenvoudig onmoontlik om hierdie vrae met pouslike finaliteit te beantwoord. Uiteindelik lê die Christelike normatiwiteit in die gewete van die enkeling of die verwante groep opgesluit. Miskien is ek daarin gelukkig dat normatiwiteit in my eie lewens- en wêreldbeskouing Christelik en Nasionaal gefundeer is, en dan in dié Christelikheid wat sy krag uit die Calvinisme put, en Nasionalisme wat in die volksverlede van die Afrikanervolk veranker lê, ingebed is.

As bloot persoonlike opmerking wil ek dit stel: ek het baie lank gelede al tot die oortuiging geraak dat die Afrikaner (Afrikaanssprekende) wat hom van hierdie belydenis losmaak, baie maklik verseild raak, saam met nuwe strominge ronddobber of deur die winde van verandering herwaarts en derwaarts geblaas word. Ek wil nie persoonlik raak nie, maar onder veral die groep sogenaamde intellektuele Afrikaners is daar 'n hele aantal wat ewe maklik van één politieke party of beweging na ' $n$ ander wip as 'n tiener na 'n nuwe liefde.

Om dan kort te gaan: Normatief positief is vir my alleen daardie kommentaar wat in die Christelike en Nasionale gefundeer is. Vir my is dit onaanvaarbaar dat in 'n boekbespreking (soos wat ek in verband met en oor 'n boek soos Kennis van die aand gelees het) bloot gepraat word van "stout", „omstrede", „uitdagend", „moedswillig", „volwasse”.

Vir my steek daar basies oneerlikheid in wanneer 'n kommentator nie die feite waaroor sy kommentaar gaan, eers duidelik stel en dan afkeur of goedkeur, vergoeilik of verdoem nie. Kommentaar wat vaag in die lug rondsweef asof die kom- 
mentator bang is dat hy die leser vooruit aanstoot sal gee wanneer hy duidelik en beslis die feitelike agter die kommentaar stel, gaan by my nie op nie. Vir my dra daardie soort kommentaar, ook binne die raamwerk van boek- en kunsbespreking net soveel gesag as die koerantopskrif dat die jongste Mej. Wêreld huis toe gestuur is omdat sy "stout" was.

Vir my lê die norm daarin dat, as iets gesê moet word, moet dit, steeds in beskaafde taal en vorm, duidelik en onmiskenbaar gesê word. Pap en halfhartige kommentaar is vir my persoonlik ewe verwerplik as die aaneenstrengeling van reekse en reekse onsmaaklikhede in 'n roman wat dan moet deurgaan as 'n "eerlike" of "betrokke" roman wat dan ook die voos kolle, die rioolvore, in die samelewing moet onthul.

Oor die onthullingstendens staan ek ewe skepties. Te veel van die sogenaamde onthullings in die pers, en deesdae blykbaar ook in ander kommunikatiewe media, ressorteer vir my onder die benaming „geelpers" of „sensasietegniek”. Die klem val in hierdie soort skryfwerk heeltemal te swaar op morsigheid ter wille van die verkoopwaarde van morsigheid. Dit is naamlik reeds ' $n$ eeu lank goed bekend dat 'n sensasiekoerant 'n veel groter oplaag kan behaal as 'n elitekoerant. Uiteindelik gaan dit om geld. En laat ons duidelik oor die saak wees. Met die „oudste beroep" kan vroue - en deesdae blykbaar ook skrywers, uitgewers en boekhandelaars, meer as die ge. middelde verdien.

\section{Vermaak}

Oor die derde funksie van die media, dié van vermaak, wil ek nie veel meer sê nie. Tot groot hoogte lê dít wat vir radio en beeldradio bedoel is, meer op die vlak van die kuns as die kommunikasiewese, maar dit werk tot sekere hoogte tot die nuusmedia deur. Dit kan miskien maklik soos volg saamgevat word: hoe meer permissief die kuns, hoe makliker vind permissiviteit sy weg na die massamedia. Hoe veelvuldiger die voorkoms van woorde wat in die massamedia nie geskryf word nie, maar met ' $n$ bepaalde getal letters van die alfabet aangedui word, in die kuns, hoe nader kom die dag dat in die kommunikasiemedia die norm aanvaar sal word dat dit wat in die kuns nie skok nie, in die koerant of tydskrif, dalk in die radionuus, radiobespreking of hoorbeeld, ook nie sal 
skok nie. Die neiging tot blatante smerigheid, naaktheid ens het in die kunste alledaags geword en die nuusmedia is op pad daarheen, maar dan stel ek dit met 'n voorbehoud: ek glo dat veral SA-koerantdireksies wat noodwendig die grootste moontlike massa lesers op die oog het, veel doeltreffender sensors sal blyk te wees as die manne van die Publikasieraad. Dit gebeur baie maklik dat ' $n$ koerant wie se kunsredakteur kwyl oor die onregte wat Breyten Breytenbach en ander Afrikaanse skrywers deur bose sensors aangedoen word, met heelwat minder moeite van 'n koerantskrywer ontslae raak as wat nodig is om 'n kennisgewing oor 'n ongewenste werkie in die Staatskoerant geplaas te kry. Om die waarheid te sê: koerantbesture verdra min nonsies.

\section{Ekonomiese oorweginge}

Dit verg weinig oorredingsvermoë om die Suid-Afrikaners daarvan te oortuig dat hul koerante merendeels met ideologiese oogmerke gestig is en in stand gehou word. In die geval van die Afrikaanse koerante en tydskrifte geld hierdie oorweging byna sonder uitsondering. Dit was maar sedert die Tweede Wêreldoorlog dat die Afrikaanslesende publiek met tydskrifte van die Keur. en Fyn Goud-soort gekonfronteer is.

Maar of 'n koerant of tydskrif (en dit geld ook die radio en beeldradio) met die fraaiste ideologiese oogmerke denkbaar gestig is, geld is vir die uitgee en voortsetting daarvan noodsaaklik. En in Suid-Afrika kom daardie geld uit net twee bronne: intekengelde en betaalde reklame. Die landsomstandighede bring mee dat min koerante en tydskrifte swaar op intekengelde kan leun: die lesers woon te verspreid en is te yl gesaai om van die miljoene-oplae van die buiteland te kan praat. Die grootste dagblad in die land sal nog 'n lang pad moet stap voordat hy die 200000 -kerf bereik en die twee grootste Sondagblaaie het nog nie die halfmiljoen-kerf goed in sig nie. Gewoonlik word in Suid-Afrika gesê dat die intekengeld nie die papier betaal wat vir die druk van die koerant of tydskrif nodig is nie.

Reklame-inkomste gee die deurslag - in Suid-Afrika in die omgewing van R80 miljoen per jaar vir alle media. En om hierdie R80 miljoen word bitter skerp gebie. Lokaas nommer een is totale sirkulasie, waarop volg: taal- én politieke 
herkoms en toekoms (Rapport het bv 'n groter netto en bruto sirkulasie as The Sunday Times, maar kry nog lank nie die Times se advertensie-inkomste nie).

'n Mens wil dit nie graag hardop sê nie, maar in die stryd om ekonomiese voortbestaan of welvaart (die ekonomiese norm genoem) word betreklik maklik op ander norme getrap. Soms word hulle heeltemal vertrap. In die jag op lesers, so het Hearst en Pulitzer reeds in die negentiger jare van die vorige eeu begryp, is die aanwending van 'n aantal wapens noodsaaklik: seksualiteit, veral kru seks, sensasie (waaronder moord en doodslag, bloed en geweld in al sy vorme - waarom vind 'n mens anders sulke groot skares, ook vroue, by boks- en stoeigevegte), onwaarskynlikhede en bo-natuurlike verskynsels, skandale van allerlei aard solank hooggeplaastes in staat of kerk maar daarby betrek kan word (so 'n restetjie uit die klassestryd). In elk geval moet daar 'n tikkie godsdiens bykom - baie potensiële lesers het immers 'n meer of minder sterke godsdiensdrang. En vir „onderdruktes" moet in die bres getree word.

Hierdie resep deug vir al die kommunikasiemedia, weliswaar nie by twéé in dieselfde verhouding nie. Dit is so dat baie gebeurtenisse sonder aandikking sensasioneel is, bv die moord op dr Verwoerd in die Volksraad. Omdat ons almal mense is, het die romantiese en erotiese 'n universele betekenis: miljoene woorde is oor die romanse van prinses Anne geskryf. Baie van ons is lief vir sport; ons stel belang in die kerklike en kulturele. Maar dikwels is die aangebode dis so sterk gekruie dat die normale mens aan die brousel stik.

Die vaslegging van ' $n$ norm wat hierdie aangeleentheid betref, is een van die neteligste dilemmas van die moderne kommunikasiewese. Word die medium saai en onaantreklik, verloor hy lesers/luisteraars/kykers en gaan hy bankrot. Word hy te kru, te robuust, te plat (soos die "humor" uit die egskeidingshof) walg dit die leser/luisteraar/kyker (in die geval van beeldradio onder meer blatante, tartende naaktheid, bestialiteit ens).

\section{Slot}

In die moderne koerantwêreld is daar deesdae in wese drie soorte koerante: plaaslike en streekblaaie, die groot nasionale 
nuusblaaie en die dikwels kleiner elitekoerante. In Europa is die aanslag en invloed van die plaaslike en streekkoerante dikwels die swaarste en grootste vanweë hul onmiddellikheid; is die groot nasionale koerante dikwels die mees sensasionele in die land, al is daar ook baie grade van sensasie, en moet die elitekoerante vir goed die helfte uit ander bronne gedra word omdat hulle ekonomies onlonend is.

Maar daardie elitekoerante - ongeveer honderd in die hele wêreld - sal steeds die ruggraat van die kommunikasiebedryf op hoë vlak bly, en wel weens die gesag waarmee hulle spreek. As Vader Times en die Guardian in Londen iets sê, bly dit gewoonlik gesê - al word albei koerante met ander middele as eie inkomste gedra. Die Presse van Wenen verloor geld, so weet almal, maar vanweë die kostelike inligting waarmee die blad verskyn, word hy deur die handels- en industriële gemeenskap van Oostenryk gedra: die volk kan sonder die blad nie die mas opkom nie.

En so het die meeste lande van die wêreld wat self op hoë vlak beweeg, 'n paar sulke elitekoerante wat aan al of byna al die norme voldoen wat aan 'n koerant gestel word; hulle lewer 'n puik universele nuusdiens, ook vertolkende en agtergrondnuus; hul kommentaar bevredig die intellektuele gemeenskap; hulle bied die beste oor geestelike strominge, die kunste en die kultuur; en hulle lewer 'n eersterangse ekonomiese nuusdiens, al is hulle soms vanweë 'n beperkte leserskring nie self die heel beste reklamemedium nie.

Dit beteken nie dat al die koerante wat nie tot dié keurbende behoort, swak is nie. Sommige is steeds eersteklas. Die verskil is bloot dit: sonder sekere goeie koerante kan die ingeligte wêreldmening klaarkom, sonder sommige nie.

G J Pienaar

$\mathrm{PU}$ vir $\mathrm{CHO}$ 